\title{
Clasificaciones documentales y procesos informativos: una vía de racionalización
}

\author{
Juan Antonio Martínez Comeche \\ Escuela Universitaria de Biblioteconomía \\ y Documentación \\ Universidad Complutense de Madrid
}

\subsection{Resumen}

Se exponen las clasificaciones más relevantes de documento establecidas entre 1960 y 1990, y los criterios en que se basan. Se contrasta con la tipología documento primario-documento secundario que se obtiene de aplicar un modelo general de proceso informativo documental. Se concluye que, conforme a este modelo, no tiene cabida la consideración de documentos terciarios o mixtos.

Palabras clave: Documento. Tipología documental. Proceso documental.

\subsection{Abstract}

The more important documentary tipologies between 1960 and 1990 and their basis are exposed. These tipologies are contrasted with the tipology obtained when we apply a general model of documentary chain. It concludes that there is no possibillities to consider the existence of terciary documents.

Keywords: Document. Documentary tipology. Documentary chain.

\section{Introducción}

La Documentación, como se ha dicho en numerosas ocasiones, es una ciencia joven que carece aún de una tradición investigadora prolongada. Si juzgamos por el número de estudios publicados en los últimos años sobre nuestra área de conocimiento, tendremos que reconocer el auge de la Documentación en todo el mundo y el ímpetu y entusiasmo que alienta a los estudiosos en materia documental.

A pesar de ello, su juventud se percibe claramente en la ausencia de una elemental unificación terminológica. Analizando, por ejemplo, una parte de la bibliografía relacionada con las unidades informativas (bibliotecas, centros de documentación, archivos...) y con los servicios que ofertan al usuario (préstamo, 
consulta, reprografía, búsquedas...) concluiremos de inmediato que existe una gran diversidad en la denominación de los diversos organismos a los que puede acudir un usuario. Nuria Amat (1988, p. 25) señala, por ejemplo, la identidad de biblioteca científica y centro documental, porque ambos efectúan los mismos procesos documentales y ofrecen idénticos servicios al usuario. La literatura anglosajona es proclive al empleo del término special libraries, mientras que «centro de documentación» es el término más empleado en España y Francia. De igual forma, primando la contemplación del proceso documentario desde el punto de vista del usuario, es muy frecuente encontrarse en los estudios sobre el tema los términos servicios de información, information services, services d'information y otros similares, frente a los autores que prefieren vocablos que contemplan el proceso desde el punto de vista del organismo que lleva a cabo las tareas documentarias, empleando términos como «centro de documentación», «unidad de información» y otros parecidos.

Esta falta de uniformidad terminológica no afecta sólo a aquellos aspectos que pueden parecer a primera vista secundarios o de menor importancia, como el de los organismos donde se llevan a cabo procesos de índole documentaria. También atañe a los conceptos medulares de la ciencia documental: la noción de información, o la de documento y su tipología, entre otros, siguen siendo objeto de análisis y discusión por parte de los estudiosos y profesionales.

La ausencia de acuerdo en la definición o conceptuación de los fenómenos esenciales de la Documentación tiene motivaciones muy diversas, entre las que destacaría dos más vinculadas con el tema que pretendo analizar a continuación. En primer lugar, hemos de reconocer que la ciencia documental posee una proyección práctica fundamental. Los profesionales de la Documentación saben que, a la postre, lo que importa realmente es satisfacer con precisión y rapidez las necesidades informativas de los usuarios que acuden a diario a su centro. Estando inmersos en la vorágine de una actividad cotidiana de índole práctica, es lógico que demanden estudios de carácter técnico que les ayuden a resolver los problemas reales con los que se enfrentan, en detrimento de los estudios de carácter teórico cuya aplicación directa o inmediata no es factible.

Sin embargo, en lo que atañe a las clasificaciones documentales de las que me ocupo aquí, creo que la existencia de estudios teóricos que pretendan alcanzar una tipología documental común, esto es, compartida en sus líneas esenciales por todos, tendría consecuencias beneficiosas en el ámbito práctico: sin duda favorecería a continuación el diseño de tratamientos similares para cada una de las clases de documentos obtenidas, sea cual sea el centro que los incorpore a su fondo, lo que facilita primeramente la labor del documentalista, que no tendría que improvisar o crear técnicas específicas en ningún caso, y al mismo tiempo asegura un mejor servicio al usuario, por cuanto éste puede acudir a varios cen-

Scire. 3 : 1 (ene. -jun. 1997) 31-53 
tros con idéntica demanda sin necesidad de ajustarla a las peculiaridades del tratamiento realizado en cada uno de ellos, lo que conlleva una mayor rapidez y exhaustividad en la obtención final de información.

La segunda causa de esta falta de normalización terminológica que quiero destacar aquí ha sido apuntada al comienzo, y tiene relación con la búsqueda de metodologías y el discernimiento de modelos teóricos apropiados a sus intereses. La participación irrenunciable del ser humano en las actividades documentales fuerza la estrecha vinculación de la Documentación con otras áreas de conocimiento muy dispares, como la Lingüística, la Psicología o las nuevas tecnologías (Informática y Telecomunicaciones entre otras), favoreciendo en consecuencia una dispersión de enfoques que derivan en resultados aparentemente irreconciliables. Como tendremos ocasión de comprobar más adelante, la tipología documental es un ejemplo más de este fenómeno, que alcanza sin embargo a todos sus ámbitos.

No es mi intención presentar aquí una clasificación novedosa que suplante a las ya existentes, pues parto de la hipótesis de que la interdisciplinariedad y complejidad intrínseca que caracteriza la Documentación hacen en teoría imposible la consecución de una única clasificación: consciente o inconscientemente estaríamos primando un enfoque sobre otro, o lo que es peor, estaríamos aunando diversos criterios sin concierto alguno.

Así pues, parece más lógico renunciar de partida a esa hipotética y exclusiva tipología. Mi objetivo, en cambio, consistirá en mostrar algunas de las clasificaciones más relevantes elaboradas por los estudiosos, tratar de discernir los criterios en los que se basan, y comprobar la utilidad de uno de los modelos de proceso informativo y proceso documental de entre los muchos posibles, a fin de racionalizar y sistematizar de forma coherente alguna de las tipologías existentes.

Por tanto, no se trata aquí de resolver directamente la falta de uniformidad terminológica, ni de llegar a un consenso final sobre la definición de ciertos tipos de documentos, sino de presentar algún criterio que, basado en un modelo teórico, permita reabrir la discusión sobre el problema de la clasificación documental de manera más sistemática.

\section{Diversos enfoques y tipologías documentales}

A fin de mostrar ordenadamente las distintas tipologías de documentos realizadas por algunos de los autores más citados en relación a este tema, seguiré un criterio cronológico, el de la fecha de publicación de los estudios de los que me he servido. Hay que advertir que este procedimiento no es totalmente exacto, dado que en unos casos he podido acceder a la versión en el idioma original,

Scire. 3 : 1 (ene. -jun. 1997) 31-53 
mientras que en otros solo he tenido a mi disposición la versión castellana posterior. Esta circunstancia, sin embargo, no invalida las conclusiones de carácter general que deseamos obtener, y nos permite alcanzar, en cualquier caso, una visión global del pensamiento de los diversos investigadores desde los años sesenta hasta la actualidad.

\subsection{Década 1960-1970}

A comienzos de los años sesenta, Otto Frank y sus colaboradores publican un estudio cuyo título en castellano es Técnicas modernas de documentación e información. En él se establece una primera clasificación que distingue entre publicaciones primarias y secundarias.

Se entiende por publicaciones primarias aquéllas «que contienen información propiamente dicha en su forma original no abreviada, tales como libros, revistas y monografías científicas»(1964, p. 19), y por publicaciones secundarias las «fichas catalográficas o extractos [de contenido] [...] y elementos similares [...] por contraposición a "publicaciones primarias" en el sentido en que se definió esta expresión»(1964, p. 48).

A su vez, entre las publicaciones primarias distingue los libros, publicaciones periódicas, separatas de artículos y recortes de diarios, patentes, normas, tesis y disertaciones (1964, p. 19-25). Los tipos principales de publicaciones secundarias que menciona son las citas bibliográficas, anotaciones y extractos de contenido, catálogos e índices en fichas y listas en forma de página (1964, p. 3044). En general, pues, se trata de obras que referencian las primarias (1964, p. 25).

Los autores, sin embargo, advierten que «existen otros tipos diversos de publicaciones y documentos que no encuadran exactamente en ninguna de las categorías mencionadas. Son importantes entre ellos, y no quedan descritos bibliográficamente en forma adecuada, las actas e informes de congresos, conferencias y simposios, como también los informes emanados de asociaciones cooperativas de investigación y de laboratorios o institutos independientes, que se publican a veces en anuarios y, en otros casos, a intervalos irregulares» (1964, p. 25).

Esta dificultad de adscripción a uno de los dos tipos surge a consecuencia de la falta de originalidad en la información aportada por el nuevo mensaje, ya que tanto los informes como las actas remiten en última instancia a una información original que se halla en los artículos de los congresistas, conferenciantes o del personal del laboratorio o de la institución. En consecuencia, no se ajustan a la definición de publicación primaria. Pero como su objetivo no es resumir o destacar tampoco lo fundamental o sustancial de esos mensajes originales, no deben ser considerados tampoco publicaciones secundarias.

Scire. 3 : 1 (ene. -jun. 1997) 31-53 
La solución a este problema podría hallarse en lo que algunos autores han denominado predocumento. Como afirma Antonio Luis García Gutiérrez (1984, p. 33), «el mismo hecho de crear un documento supone un problema de recepción e interpretación que convierte al emisor en intermediario entre la naturaleza y la colectividad de receptores». En efecto, todo documento implica la observación previa por parte de un ser humano de un fenómeno material o ideológico, a raíz del cual emite un mensaje que pretende explicarlo, justificarlo o simplemente darlo a conocer. Pues bien, es la distinta naturaleza de este fenómeno previo el que origina necesariamente documentos dispares. En el caso que nos ocupa, cada uno de los congresistas y de los investigadores del laboratorio o del instituto de investigación ha contemplado un hecho, suceso o ente físico o intelectual sobre el que ha creado un mensaje original, denominado habitualmente documento cuando ha sido incorporado a un soporte. Además de todos esos procesos individuales de creación de documentos, otros seres humanos observan el fenómeno por el cual algunos de esos investigadores se reúnen en un lugar y fechas determinados para hacer partícipes a los demás de sus ideas y conclusiones. Como vemos, ese evento -el congreso- constituye un fenómeno que puede ser documentado independientemente de cada uno de los mensajes emitidos por los congresistas, aunque esté relacionado con ellos. De lo expuesto deducimos que las actas o informes de congresos o actividades se ajustan a la definición que Stekhoven aporta de publicación primaria, y entre ellas deben incluirse.

En conclusión, Otto Frank y sus colaboradores establecen una tipología documental que distingue entre publicaciones primarias y secundarias, basada en dos criterios: originalidad y extensión primigenia como distintivo de la publicación primaria; y al contrario, ausencia de estas dos propiedades en la publicación secundaria, que se limita a referenciar brevemente, tanto en sus aspectos formales como de contenido, la documentación primaria.

A finales de los años sesenta, Mijailov y Guiliarevskii advierten que esta división entre documentos científicos primarios y secundarios «es bastante convencional y aproximada, porque en buena medida no se refiere a los documentos, sino a la información científica que contienen» (1968, p. 21). Además, muchos documentos científicos «contienen tanto los resultados de la propia investigación como el procesamiento de información extraída de publicaciones anteriores» (1968, p. 21), por lo que los documentos científicos suelen presentar conjuntamente las características de la documentación primaria y secundaria si la concebimos en base a la originalidad. Sin embargo, no hallando un criterio sustitutivo apropiado, admiten finalmente esta clasificación, y definen documentos primarios como «aquellos documentos y publicaciones que contienen principalmente nuevos conocimientos científicos o nuevas visiones de hechos o ideas conocidos» (1968, p. 21), mientras que los documentos secundarios se

Scire. 3 : 1 (ene. -jun. 1997) 31-53 
caracterizan porque «sirven preferentemente para informar sobre los documentos primarios» $(1968$, p. 21).

En resumen, dos aspectos novedosos resaltan en el Curso introductorio de informática-documentación de Mijailov y Guiliarevskii: en primer lugar, la constatación de la existencia de dos elementos básicos en el término documento (información y aspecto material), lo que les induce a definir documento como «cualquier objeto material que registra o prueba algún conocimiento y que puede ser incluido en una determinada colección» (1968, p. 21). De este modo, la distinción entre documento primario y secundario puede concretarse aún más, adoptando como criterio la originalidad de la información contenida en el documento. En segundo lugar, se pone de relieve la insuficiencia de este principio de originalidad para distinguir de por sí la documentación primaria de la secundaria, lo que fuerza a definir aquélla como la que contiene principalmente información original, ya que habitualmente incluye también información / documentación secundaria. A su vez, conviene resaltar que esta documentación secundaria se distingue asimismo por la ausencia mayoritaria de originalidad en la información que aporta, de manera que puede informar brevemente tanto del contenido como de aspectos más formales de la documentación primaria. Así, no debe extrañar que además de las bibliografías, catálogos o resúmenes, Mijailov y Guiliarevskii incluyan entre los documentos secundarios las enciclopledias y los diccionarios, o cualquier texto que recopile datos de cualquier índole ya conocidos (1968, p. 42-45).

En su obra Fundamentos de la informática (cuya edición castellana apareció en 1973), Mijailov, Chernii y Guiliarevskii insisten en los inconvenientes del criterio de originalidad de la información para efectuar una clasificación en documentos primarios y secundarios (1973, p. 79-80). Añaden, pues, otra que distingue entre documentos publicados e inéditos, en la que observan igualmente un inconveniente de carácter histórico: «Hace varias décadas el límite entre ambos estaba claramente definido. El único medio seguro de reproducción en múltiples tiradas de los documentos era la imprenta, y la mayor parte de las obras impresas se sometía a recuento y registro bibliográficos. Se consideraba que las ideas y los hechos sólo tenían vigencia científica después de ser publicados, lo que al mismo tiempo entrañaba cierta divulgación y registro oficial de los documentos donde aparecían. El surgimiento de los modernos medios de reproducción, la extensión de la actividad bibliográfica a algunos materiales inéditos y la aparición de formas intermedias (preprints, traducciones de artículos de revistas) dificulta en algunos casos la delimitación de las ediciones impresas y de los manuscritos» (1973, p. 80).

Scire. 3 : 1 (ene. -jun. 1997) 31-53 


\subsection{Década 1970-1980}

Hemos visto cómo en los años sesenta la discusión en relación a la tipología documental se centra en la dicotomía documento primario frente a documento secundario, basada en el criterio de originalidad informativa, señalándose finalmente sus inconvenientes. La década de los años setenta, en cambio, se caracteriza por una apertura mayor en cuanto a los posibles criterios de clasificación, sin abandonar por ello el análisis de la documentación primaria y secundaria.

Uno de los autores más representativos de la década en este sentido es Couture de Troismonts. En su obra Manual de técnicas en documentación (1975) el autor amplía el número de criterios de clasificación, al tiempo que rechaza la simplicidad de una tipología que distingue entre documentos primarios y secundarios.

En relación a este último aspecto, Couture de Troismonts (1973, p. 8-9). prefiere hablar de cuatro categorías documentales, definidas así:

- Documentos iniciales: Primeras manifestaciones del hombre para fijar un conocimiento. Ejemplos: manuscritos, notas de laboratorio, mediciones, apuntes de viaje, fotografías, pictografías rupestres.

- Documentos originales o primarios: Primeras formas de transposición de los documentos iniciales. Ejemplos: versión mecanográfica de un manuscrito, primera edición de un libro, grabación magnetofónica directa, etc.

- Documentos secundarios: Comprenden documentos derivados de los primarios, no habiendo por lo tanto una creación o investigación original. Ejemplos: segundas y sucesivas ediciones, índices, bibliografías de segunda mano, etc.

- Documentos terciarios: Documentos reproducidos por un medio mecánico, sin modificación del original. Ejemplos: reproducciones facsimilares, fotocopias electrostáticas y por otros sistemas similares, etc.

Como puede observarse, Couture de Troismonts no niega el criterio de originalidad, pero considera imprescindible situarlo en un contexto más amplio que modifica su naturaleza. Este contexto es el proceso que abarca desde el momento en que el ser humano fija por primera vez en un soporte el conocimiento hasta que finalmente es reproducido por un medio mecánico, ya sin intervención del autor. En esta cadena en la que se ve inmersa el documento, Couture establece dos divisiones sucesivas: una primera que distingue la producción de los tratamientos sucesivos a que son sometidos los documentos, cuyo criterio distintivo, inicialmente, sigue siendo la originalidad. Así, tanto los documentos iniciales como los primarios son originales, mientras que los documentos secundarios y terciarios no son originales, sino derivados de los primarios. Hay que notar aquí

Scire. 3 : 1 (ene. -jun. 1997) 31-53 
que el criterio de originalidad, en este contexto, ha modificado sustancialmente sus características. No se trata ya de la originalidad de la información contenida en el documento, como defendía Mijailov, sino de la originalidad del documento en su totalidad. En efecto, tanto un documento terciario (reproducción por fotocopia, por ejemplo) como un documento primario (el ejemplar que se ha reproducido) son idénticos en lo que atañe a la originalidad de la información que portan, y sin embargo, son muy diferentes para Couture. Si nos fijamos, con este nuevo enfoque Couture trata de solventar la dificultad expuesta por Mijailov, Chernii y Guiliarevskii, en el sentido de que la tradicional distinción entre documentos primarios y secundarios se basaba a la postre en la originalidad de la información, no en la del documento, y que este criterio no era suficiente desde el momento en que un documento primario suele contener información secundaria. Ante el inconveniente, Couture propone una clasificación inicial que tiene en cuenta la originalidad del documento en su integridad; esto es, no únicamente la originalidad de la información, sino al mismo tiempo la de la incorporación o fijación de esa información o conocimiento en un soporte.

Habiendo considerado simultáneamente el documento en sus dos aspectos esenciales (mensaje y soporte), el criterio de originalidad del documento fuerza una primera subdivisión cuyo límite se halla en el sometimiento de ese documento original (un mensaje novedoso en su soporte inicial) a cualquier tratamiento posterior que lo modifique tanto en su contenido como en su forma material. De ahí que posteriormente nuestro autor hable de documentos secundarios (no originales por modificación del mensaje y del soporte simultáneamente) y de documentos terciarios (cuando el tratamiento afecta exclusivamente al soporte). Así, dentro de los documentos secundarios se encuentran tanto las referencias bibliográficas como las nuevas ediciones de un texto, pues en ambos casos se origina un texto nuevo (en las sucesivas ediciones porque se amplía, corrige o revisa el original; en las referencias bibliográficas porque se origina un texto distinto que lo identifica formalmente o en su contenido).

Por último, dentro de los documentos originales, Couture establece igualmente una nueva división, que trata de llamar la atención sobre el propio proceso de producción del documento. Un primer estadio englobaría todos los pasos previos de mensajes fragmentarios o incompletos fijados a soportes provisionales, al que Couture denomina documentos iniciales, mientras que solo el mensaje genuino incorporado al soporte inicial definitivo constituiría el documento primario.

En definitiva, tres criterios se aúnan en la tipología de Couture de Troismonts: originalidad del documento, estadio o grado de producción y nivel de tratamiento posterior, que en su conjunto permiten al autor que nos ocupa distinguir cuatro categorías de documentos.

Scire. $3: 1$ (ene. -jun. 1997) 31-53 
Por estas fechas, el término 'documento terciario' cobró fortuna en las investigaciones sobre el tema, empleándose en general el vocablo para designar documentos sometidos a un nivel de tratamiento distinto al habitual en los documentos secundarios, y en consecuencia, difícilmente enmarcables en ninguna de las categorías esenciales. Emilia Currás (1975, p. 267) resumía de este modo la opinión más extendida en los estudios de aquella época:

«En la reciente literatura sobre este tema se encuentran los siguientes tipos de documentos científicos: documentos primarios, documentos secundarios y documentos terciarios.

- Documentos primarios son aquellos que se producen como primera consecuencia de un estudio, una investigación, un trabajo. Se consideran aquí los artículos de revistas - por tanto las revistas o publicaciones periódicas, las tesis doctorales, los preprints, las monografías, las separatas, las publicaciones de Congresos, etc.

- Documentos secundarios son los que surgen como consecuencia de los primarios, es decir, aquellos que resumen éstos, o los tratan de alguna manera. Así tenemos las bibliografías, revistas de resúmenes o abstracts, revistas de títulos, etc.

- Documentos terciarios serán, a su vez, consecuencia de los secundarios, de manera que encuadraremos aquí las bibliografías de bibliografías, las bibliografías críticas selectivas como por ejemplo los «Annual Reports» o los «Progress», entre otros» (1975, p. 267).

En esta tipología, frecuente en los tratados de entonces, tal como señala Emilia Currás, se observa un seguimiento del principio básico que guió a Couture de Troismonts, esto es, la consideración del proceso íntegro que sufre el documento desde su creación hasta que llega a manos del receptor. En este camino, el documento original puede verse indudablemente sometido a multitud de tratamientos sucesivos más allá del simple análisis formal o de contenido. La consideración del documento terciario como aquel documento secundario que es tratado nuevamente para constituir un mensaje posterior basado en él (el caso de las bibliografías de bibliografías) antes de ser utilizado por el receptor, confirma a la postre un intento por abarcar en detalle todas y cada una de las transformaciones que puede seguir un documento original.

Sin embargo, la diferencia entre la tipología de Couture y la generalización adoptada posteriormente es sustancial. Couture, consciente de las dificultades que acarrearía la consideración de la totalidad de los hipotéticos tratamientos posteriores a la producción del documento original como base para establecer una tipología documental, no contempla la cadena en sí misma, es decir, los sucesivos pasos por los que atraviesa el documento, como criterio que permite

Scire. 3 : 1 (ene. -jun. 1997) 31-53 
discernir categorías diversas. Al contrario, partiendo de la existencia de tales procesos, considera únicamente aquéllos que repercuten de una manera sustancial en el documento original, de manera que sólo aquellos tratamientos que modifican el mensaje o el soporte iniciales dan lugar a una categoría documental distinta. Contemplado así, una bibliografía de bibliografías supone un documento derivado de originales que ha transformado tanto el mensaje como el soporte originarios, y en consecuencia, es un simple documento secundario. Dicho de otra manera, para Couture de Troismonts tanto los documentos secundarios como los terciarios derivan directamente de los primarios: los secundarios ven afectados el mensaje y el soporte primigenios, mientras que los terciarios exclusivamente el soporte.

En cambio, la consideración de un documento terciario como aquél derivado de un secundario implica en última instancia que cada transformación origina una categoría diferente (un documento primario se transforma en secundario, éste en la cadena se modifica en un terciario, y así sucesivamente). En definitiva, se está considerando cada eslabón de la cadena como criterio suficiente para el establecimiento de nuevos tipos de documentos. Como es lógico deducir, este enfoque introduce un elemento peligroso desde el punto de vista teórico: la imposibilidad de limitar el número de transformaciones a las que puede ser sometido un documento primario. Antonio Luis García Gutiérrez ha explicado este fenómeno con las siguientes palabras: «La cadena que pueden generar las bibliografías (bibliografía de bibliografías de bibliografías de...) según las facetas y especialidades científicas, tiende al infinito, y de ese tenor, la clasificación tipológica se haría inagotable (cuaternarios, etc.), lo cual no parece operativo a efectos de claridad de los tipos de documentos» (1984, p. 55).

Como apuntamos anteriormente, en esta década se introducen una mayor variedad de criterios a la hora de establecer clasificaciones documentales. En este sentido, una de las más representativas es la de José López Yepes (1978), quien parte de la propia noción de documento y de sus características esenciales para, a raíz de ellas, establecer una triple categorización correspondiente a cada uno de los aspectos primordiales que definen el documento. En palabras de José López Yepes, «una teoría de la tipología del documento científico debe esbozarse a partir de un triple criterio que se corresponde con la triple esencia del documento: el soporte físico, la objetivación de un conocimiento en el mismo y la posibilidad de transmisión o difusión del conocimiento sustentado en el documento y actualizado en el proceso de la Documentación. En base a esta consideración, los documentos científicos pueden clasificarse a efectos de: a) la naturaleza del soporte; b) desde la perspectiva de su contenido cognoscitivo y subsiguiente tratamiento dentro del proceso documental como fuentes de información, y c) desde la perspectiva de su difusión. Establecemos, de este modo, una

Scire. 3 : 1 (ene. -jun. 1997) 31-53 
primera clasificación de los documentos científicos según los niveles físico, informativo y difusivo:

a) Nivel físico o de soporte:

1. Documentos gráficos.

2. Documentos iconográficos.

3. Documentos fónicos.

4. Documentos plásticos.

5. Documentos multi-media.

b) Nivel informativo o de contenido:

1. Documentos primarios.

2. Documentos secundarios.

3. Documentos terciarios.

c) Nivel de difusión:

1. Documentos publicados.

2. Documentos inéditos.

3. Documentos reservados.» (1978, p. 110-111).

Por su parte, Couture de Troismonts (1975, p. 21-24) añade a la clasificación analizada ya, otras posibles categorizaciones de los documentos en relación a diversos criterios, a las que denomina formas documentarias. Entre ellas destacaría dos: una relativa al sentido humano empleado en la percepción del documento (forma sensible visual, auditiva y táctil), y otra que tiene en cuenta las transformaciones principales a las que puede ser sometido el documento primario cuando ha sido editado (edición original, reproducción, modificación).

\subsection{Desde 1980 hasta la actualidad}

Si en los años setenta se inicia el establecimiento de tipologías documentales conforme a diversos criterios, y se intenta profundizar en los principios que permitan definir unívocamente la documentación primaria, secundaria y terciaria, desde 1980 hasta hoy los estudios sobre tipología documental se caracterizan por un aumento notable de los posibles criterios de clasificación y por la tendencia, considerada como necesaria, bien a ampliar los límites conceptuales de cada uno de los tipos de documentos (por ejemplo, los terciarios), bien a ampliar el número mismo de tipos posibles (primarios, secundarios, terciarios y documentos de referencia, por ejemplo). Ello se debe, sin duda, al avance de las nuevas tecnologías de la información (forzando la actual consideración de los documentos electrónicos como una clase más de documento) y a una mayor complejidad en las actividades que pueden realizar los organismos documentales.

Scire. 3 : 1 (ene. -jun. 1997) 31-53 
Como botón de muestra sobre este último fenómeno, que afecta indudablemente a los aspectos teóricos aquí considerados, Guinchat y Menou (1992, p. 374-375) señalan la compilación de informaciones suministradas por una pluralidad de fuentes, el análisis de la información (consistente en describir la información que contienen los documentos sobre un campo determinado, lo que permite encontrar los documentos que corresponden a una determinada situación), la evaluación de la información (o sometimiento de una información o una serie de informaciones sobre un tema particular a la consideración de uno o varios especialistas, que realizan un examen crítico y determinan su valor en general o con relación a una utilización específica), la verificación de la información (consistente en comprobar la validez de la información que contienen los diversos documentos, o en definir sus límites y en confrontar la información suministrada por diferentes fuentes sobre un asunto preciso con el fin de obtener una información acumulativa y evaluada) y la extracción de datos (o estructuración no de las referencias de los documentos, aunque en caso necesario pueden aparecer, sino de las informaciones factuales, muy precisas, que se han extraído), etc.

La aparición de nuevos soportes, resultado del progreso técnico, ha forzado la ampliación de los tipos de documentos cuando se considera como criterio de clasificación el soporte del documento o la forma de representación del mensaje en el soporte. En el primer caso, Nuria Amat i Noguera (1988, p. 20) diferencia cuatro clases de documentos (documentos en forma de papel, en película, en forma magnética -discos y cintas magnéticas- y en forma electrónica -discos ópticos-). En el segundo caso, José López Yepes (1995, p. 106), por la forma de representación del mensaje en el soporte físico, distingue entre documentos gráficos, iconográficos, fónicos, audiovisuales, plásticos y electrónicos. María Pinto Molina (1992, p. 40), siguiendo una división semejante, prefiere denominar estos últimos documentos legibles por máquina.

La expansión de criterios, y la consiguiente aparición de nuevas tipologías que origina, puede comprobarse en las clasificaciones que recientemente ha incorporado José López Yepes en uno de sus últimos trabajos (1995, p. 106107). Además de la apuntada en el párrafo anterior, la que tiene en cuenta el nivel de difusión y la basada en el grado de modificación de la naturaleza del mensaje -presentes en estudios anteriores, con la salvedad de eliminar en esta última los documentos terciarios-, López Yepes ha añadido nuevas clasificaciones conforme al grado de originalidad en la creación del documento (distinguiendo entre fuentes y bibliografía), al grado de transformación del mensaje documentario soportado en el documento (dando lugar a mensajes documentados, mensajes marginales, mensajes referenciales y mensajes documentales), a su situación en el sistema de las ciencias (documentos jurídicos, matemáticos, médicos,etc.) y finalmente conforme al grado de permanencia del mensaje a lo

Scire. 3 : 1 (ene. -jun. 1997) 31-53 
largo del tiempo (permitiendo discernir entre documentos científicos y no científicos).

Guinchat y Menou (1992, p. 41-53) añaden todavía algún criterio más de clasificación a los ya expuestos. Así, en relación a las formas de producción, distinguen entre documentos en bruto (tal como se encuentran en la naturaleza: muestras de tierra, minerales, plantas...) y documentos manufacturados (fabricados por el hombre o creaciones intelectuales); en cuanto a las modalidades de utilización, distinguen los documentos que pueden utilizarse directamente por el hombre de los que requieren un equipamiento especial; por su forma de publicación, estos autores hablan de documentos publicados (distribuidos comercialmente) y no publicados (no comercializados y de difusión más o menos restringida); por último, apuntan otros posibles criterios: el tema tratado en el documento, la forma de presentación del tema, el nivel científico o el grado de originalidad y de novedad, entre otros.

En resumen, parece claro que los criterios de clasificación se han multiplicado en los últimos quince años, y que la lista de posibilidades debe permanecer siempre abierta. Pero ello no obsta para que se deba procurar, desde un punto de vista teórico, organizar esos criterios de acuerdo a algún principio rector que los estructure y permita situar cada uno de ellos en relación a los demás. Se evitaría de este modo la sensación de caos que empieza a dominar los estudios sobre clasificaciones documentales, y sobre todo permitiría identificar aquellos criterios que, aunque útiles en circunstancias específicas, no deben ser incluidos en las tipologías de carácter general porque aúnan o entremezclan criterios ya considerados previamente como primordiales. En el siguiente apartado intentaremos mostrar una posible vía de racionalización de los criterios de clasificación, cuya existencia empieza a ser necesaria.

La multiplicación de clasificaciones que caracteriza los estudios aparecidos en estos últimos años no ha erradicado la discusión sobre la tipología más tradicional y más dificultosa de establecer, la relativa a la documentación primaria, secundaria y terciaria, a juzgar por la falta de consenso que muestran los estudiosos. Como ya se ha indicado anteriormente, la aparición de nuevos productos documentales ha complicado aún más el panorama teórico, dificultando sobremanera el deseable entendimiento en este aspecto.

Nuria Amat i Noguera (1988, p. 20) apela inicialmente al contenido de los documentos para distinguir finalmente entre «a) Primarios: publicaciones originales presentadas íntegramente; b) Secundarios: representación condensada de documentos primarios; c) Terciarios: listas de publicaciones secundarias; d) Documentos de referencia: documentos de consulta cuya disposición interior permite y facilita la información rápida, precisa e inmediata». 
Como podemos observar, dos criterios permiten discernir claramente los primarios de los secundarios: la originalidad del contenido y la presentación íntegra o condensada de ese mismo contenido. Por otra parte, la definición que aporta esta autora de la documentación terciaria (listas de publicaciones secundarias) parece aludir a un tratamiento posterior a la que se somete cierta clase de documentación secundaria, la publicada. En cuanto a la documentación de referencia (diccionarios, terminologías, etc.), compartiría con la documentación primaria el hecho de que portan información original, distinguiéndose de ella por una presentación distinta. En conclusión, la originalidad del contenido, la presentación íntegra o condensada, la disposición interior de la información y el tratamiento posterior configuran una cuádruple tipología documental.

Guinchat y Menou (1992, p. 46) emplean el grado de elaboración como criterio que «permite establecer una distinción entre documentos primarios, secundarios y terciarios.

- Los documentos primarios (o primeros) son documentos originales elaborados por el autor.

- Los documentos secundarios son documentos que se refieren a los documentos primarios y que no existirían sin ellos; contienen la descripción de los documentos primarios: bibliografías, catálogos, revistas de resúmenes, etcétera.

- Los documentos terciarios son documentos establecidos a partir de los documentos primarios y/o secundarios; reúnen, condensan o elaboran la información original en una forma que corresponde a las necesidades de una categoría de público: elaboración de síntesis, balances, situación de un problema, etcétera».

En esta última definición quizá ha influido la posición mantenida por la UNESCO en el proyecto UNISIST II, según la cual la documentación terciaria «es el resultante de la transformación (por agrupación o afinidad) de información primaria y secundaria disponible a fin de explicarla o presentarla de una forma conveniente a los usuarios como un nuevo documento que puede ser tratado como los primarios» (cit. por García Gutiérrez, 1984, p. 56).

En cualquier caso, el inconveniente que se observa en esta definición de documento terciario es su consideración, a la postre, como una simple selección y reorganización de documentación primaria o fragmentos de documentos primarios con el fin, eso sí, de responder mejor a las necesidades informativas específicas del usuario o de los usuarios que la demandan. Dicho de otro modo, se trataría de elaborar un nuevo mensaje partiendo exclusivamente de los que están a disposición del organismo. 
Pero si reflexionamos brevemente, convendremos en que, a efectos teóricos, en poco se diferencia de un resumen conjunto de varios textos o de un extracto, por cuanto éstos son igualmente nuevos mensajes que dependen exclusivamente de los originales. Concebida así, pues, la documentación terciaria no existiría sin la primaria; describe los documentos primarios, como puede hacerlo cualquier documento secundario; y por último se refiere igualmente a los documentos primarios, en cuanto incorpora explícitamente mensajes referenciales, o en su caso porque implica exclusivamente una elaboración -es el criterio puesto de manifiesto por sus autores- de la documentación primaria. En definitiva, cumple todas las condiciones impuestas por los autores para ser documentación secundaria, y por tanto, se deberían incluir en ese grupo. Se trataría, pues, de un caso particular de documentación secundaria.

Más coherente, desde el punto de vista teórico, es la visión que ofrece Antonio Luis García Gutiérrez (1984, p. 53-64). Enfocando la tipología desde la perspectiva del contenido informativo del documento, establece una cuádruple distinción:

- Documento científico primario: información generada de una investigación original fijada en un soporte transmisible y durable: libros y folletos, tesis de doctorado, actas, monografías (1984, p. 53).

- Documento secundario: elaboraciones técnicas de los documentos primarios con objeto de hacerlos más identificables y accesibles: bibliografías, índices, boletines de sumarios, catálogos de bibliotecas, guías de fuentes (1984, p. 53-54).

- Documento terciario: aquél que contiene información original (no hace referencia directa a otra información) presentada con estructura típicamente secundaria: diccionarios, léxicos, tesauros, clasificaciones, etc. (1984, p. 56)

- Documento mixto: transformaciones de originales que aportan a su vez la visión o el criterio del analista y que van acompañadas de referencias secundarias: resúmenes analíticos y extractos (1984, p. 56).

García Gutiérrez se sirve inicialmente de la originalidad del contenido para discernir dos clases básicas de documentación: la primaria y terciaria, que implican un contenido informativo original, y la secundaria, que no aporta en ningún caso información original, sino que se limita a identificar formalmente los documentos primarios.

Ahora bien, el autor observa que en ciertas ocasiones encontraremos documentos «que ofrecen las características propias de los secundarios, es decir, son referencias de originales, pero suponen una cierta transformación del documen 
to primario» (1984, p. 56), por lo que se hace necesario el establecimiento de una nueva clase que denomina documentos mixtos.

En principio, podría parecer que los documentos mixtos, en terminología de García Gutiérrez, se identifican con los documentos que Guinchat y Menou denominan terciarios, desde el momento en que ambos suponen una transformación o elaboración de documentación primaria; en definitiva, una síntesis o extracto de un conjunto de documentos originales. De ser así, la objeción que entonces se hizo a la consideración de los documentos terciarios podría hacerse ahora extensiva a los documentos mixtos. Anteriormente se concluyó que eran nuevos mensajes que se limitaban a describir los documentos primarios, sin aportación original ninguna, de manera que debían ser considerados como un caso peculiar de documentación secundaria.

Sin embargo, García Gutiérrez introduce en la definición que aporta de documento mixto un aspecto novedoso que deja íntegra la coherencia de la clasificación que aporta. Aludo a la necesaria presencia de «la visión o el criterio del analista» en el concepto de documento mixto, aspecto éste que el autor explica con más detalle en diversos pasajes de su obra Lingüística documental, diciendo que «a pesar de las llamadas a la objetividad latentes en las distintas normativas internacionales en materia de resúmenes, el especialista puede plasmar su propio sello selectivo en el contenido y forma del resumen. Es en el esfuerzo intelectual de síntesis y coherencia del mensaje, donde el sujeto ejecutor del resumen rompe con las barreras de la información primaria y secundaria» (1984, p. 127). La subjetividad que caracteriza el documento mixto se plasma, pues, en la capacidad de selección de datos, de enfoque y de interpretación (1984, p. 56), convirtiendo el mensaje resultante en una «verdadera síntesis de las investigaciones, tamizadas [la cursiva es mía] por el ojo experto y analítico del especialista» (1984, p. 63). Como es lógico esperar, los resúmenes analíticos que incorporan este componente creativo sustancial exigen, por parte del usuario, confianza en un intermediario desconocido (1984, p. 127), estimando tanto su fidelidad al contenido del original como la valoración de las fuentes que realiza ese intermediario.

En consecuencia, para García Gutiérrez el criterio de originalidad de contenido permite sumar a la dicotomía básica originalidad / no originalidad un tercer componente, el de la existencia simultánea de ambas (documento parcialmente original y al tiempo parcialmente deudor de la documentación primaria que resume). En estas circunstancias surge el documento mixto, denominación que refleja de manera expresiva su naturaleza.

Si la documentación no original determina la existencia de documentos secundarios exclusivamente, y la mezcla originalidad/no originalidad da lugar

Scire. $3: 1$ (ene. -jun. 1997) 31-53 
únicamente a documentos mixtos, cuando la información contenida en el documento es estrictamente original pueden discernirse dos clases documentales. El criterio invocado por García Gutiérrez en este caso alude a la estructura formal o modalidad de exposición de los datos originales.

Conforme a este enfoque añadido, cuando la información original se organiza en torno a tres ejes primordiales (planteamiento o laguna que la investigación pretende cubrir o resolver, metodología aplicada y conclusiones originales aportadas) nos hallamos ante documentos primarios (1984, p. 64). En cambio, si la información original está presentada con una estructura típicamente secundaria, es preferible hablar de documentos terciarios (1984, p. 56).

En conclusión, García Gutiérrez se sirve de dos criterios (originalidad de contenido y estructura formal) para originar una cuádruple clasificación documental.

\section{Clasificación documental y procesos informativos}

Este breve repaso de algunas de las soluciones aportadas por los estudiosos en relación a la tipología documental en los últimos treinta años permite resaltar inicialmente algunas características generales, entre las que destacaría las siguientes:

1. En la década de los años sesenta se estableció una clasificación documental que distinguía básicamente dos clases de documentos, los primarios y los secundarios. Dicha tipología se apoyaba primordialmente en el criterio de originalidad de la información contenida en el documento.

2. Los inconvenientes que presentaba este criterio se pueden sintetizar en dos: en primer lugar, la habitual presencia de información referencial en la documentación primaria, por lo que la distinción no es tajante; y en segundo lugar, la existencia de obras basadas en datos que, estrictamente hablando, son conocidos (actas, informes, enciclopedias, diccionarios), pero que acarrean una faceta creativa de selección, síntesis y exposición que exige considerar un grado variable de originalidad.

3. Estas objeciones han provocado posteriormente la consideración de la dicotomía documento primario/documento secundario como excesivamente simple. Las propuestas desde entonces hasta hoy adoptan dos soluciones esenciales comunes: una primera consistente en seguir respetando el criterio de originalidad en cuanto afecta al descubridor inicial de una idea, dato o fenómeno. Enfocado así, el documento primario no plantea dudas, pues incluye siempre un contenido novedoso, desconocido hasta entonces, resultado de la investigación realizada por su

Scire. 3 : 1 (ene. -jun. 1997) 31-53 
autor. La segunda solución común consiste en ampliar las categorías documentales derivadas de ese documento primario, teniendo en cuenta ahora multitud de aspectos relativos a la naturaleza y grado de la transformación posterior operada sobre la documentación primaria.

4. La multiplicidad de criterios (aplicados con mayor o menor coherencia teórica) presente en el discernimiento de la documentación no primaria (cuyas denominaciones son muy variadas, destacando los términos 'secundaria' y 'terciaria'), origina paralelamente la aparición de tipologías complementarias conforme a enfoques muy diversos, entre los que destacan el tipo de soporte, la clase de mensaje (textual, fónico, gráfico...) y el nivel o grado de difusión.

De todo ello se deduce la necesidad, cada vez más urgente, de introducir un factor o elemento nuevo que facilite al menos la discusión y el estudio de la tipología documental, haciéndola más coherente y racional. No se trata de alcanzar aquí el consenso definitivo, presentar una clasificación inamovible y sus correspondientes denominaciones finales, sino de proponer un enfoque que puede facilitar el análisis tipológico.

En este sentido considero de gran utilidad la utilización de modelos teóricos que esquemáticamente muestren los procesos medulares que lleva a cabo la Documentación, permitiendo situar adecuadamente el documento en cada momento del tratamiento a que es sometido. De este modo se facilitaría la elección de los criterios más pertinentes según sea su situación en relación a los distintos eslabones que componen la cadena documental.

Podemos distinguir dos fases básicas de carácter general desde el momento en que el autor piensa y redacta, por ejemplo, un cierto mensaje, hasta que finalmente es puesto a disposición de un usuario en una biblioteca o centro de documentación:

a) Una primera fase de creación de ese mensaje y de incorporación a un soporte inicial (pensemos, siguiendo con el ejemplo anterior, en la creación y edición de un libro). Esta primera fase ha sido explicada por López Yepes (1978, p. 103) diciendo que «contempla la retención del mensaje, del contenido informativo en el documento, retención que, como se ha indicado, ha de ser realizada en un soporte de permanente duración. El resultado es el documento».

b) Una segunda fase por la que el documento es incorporado a una colección concreta y es esencialmente analizado, conservado y difundido activamente con el objeto de ayudar a resolver las necesidades informativas de los usuarios. En definitiva, esta fase contempla la inserción del documento en un proceso documental posterior a la primera fase

Scire. $3: 1$ (ene. -jun. 1997) 31-53 
expuesta (López Yepes, 1978, p. 103). Conviene resaltar aquí que el resultado más llamativo de esta segunda fase consiste en la creación y elaboración, por parte del documentalista, de nuevos mensajes basados en los documentos que son sometidos al proceso de análisis.

Teniendo únicamente en mente este esquema estamos en condiciones ya de destacar una circunstancia peligrosa, desde el punto de vista puramente teórico, presente en las tipologías examinadas. Dijimos anteriormente que todas las propuestas en los últimos veinte años adoptaban dos posturas comunes: una primera que concebía el documento primario como aquel mensaje original fruto de la labor creativa de un autor; y una segunda que subdividía la documentación restante (secundaria, terciaria,...) según la clase de tratamientos posteriores efectuados sobre el documento primario.

Ahora bien, el criterio de originalidad afecta a la primera fase enunciada (creación del mensaje primigenio e incorporación a un soporte inicial), mientras que la documentación secundaria, terciaria, etc., está situada en la segunda fase, de naturaleza documental, configurando los diversos productos documentales obtenidos tras la tarea de análisis.

Así pues, es posible que las clasificaciones estudiadas estén sirviéndose conjuntamente de dos criterios tan dispares que resultan en la práctica difícilmente compatibles, o cuando menos equívocos, porque sitúan en un mismo plano dos situaciones radicalmente opuestas tanto cronológica como informativamente hablando. Este fenómeno, en principio, justifica de por sí las dificultades encontradas por los investigadores a la hora de establecer sus tipologías.

En consecuencia, el criterio en pura lógica más apto y simple para establecer una tipología documental que desee considerar todas las posibles elaboraciones que la Documentación lleva a cabo con los documentos que incorpora a su fondo, verdadero campo de batalla no resuelto a juzgar por las tipologías vistas, consistiría en señalar o apuntar la existencia de tales elaboraciones. Dicho de otro modo, dado que en el esquema general apuntado esas elaboraciones o transformaciones del mensaje se circunscriben a la fase de análisis (única que contempla la posibilidad de creación y producción de mensajes distintos a los incorporados), el criterio lógico sería distinguir los documentos de entrada y de salida de esa fase de análisis.

Conforme a este criterio de elaboración o transformación del documento incorporado al fondo, obtendríamos una clasificación dual que distinguiría entre documentación primaria y secundaria, cuyas definiciones podrían ser las siguientes:

- Documentación primaria: aquel documento o conjunto de documentos incorporado física (libros, mapas, cintas...) o formalmente (monumentos,

Scire. $3: 1$ (ene. -jun. 1997) 31-53 
por ejemplo) a una colección, sobre el que se efectúa un proceso de naturaleza analítica.

- Documentación secundaria: aquel documento o conjunto de documentos resultado del tratamiento analítico efectuado sobre la documentación primaria correspondiente.

Dado que el criterio solo hace referencia a la existencia de tales elaboraciones, sin tratar de discernir sus clases, podemos concluir que, conforme a este criterio, no tiene cabida la consideración de documentación terciaria, mixta o cualquier otra.

Enfocando de este modo la clasificación, deducimos que no pueden existir documentos terciarios. Trataré de explicar el motivo de carácter teórico que justifica esta afirmación. Si nos fijamos, observaremos que el esquema de proceso documental expuesto es recurrente, es decir, puede llevarse a cabo cuantas veces se desee en un plazo temporal ilimitado, pero su repetición indefinida (por la misma o por distinta institución documental) en nada modifica las características que adquiere el mensaje, siempre las mismas cada vez que recorra estas fases esenciales que componen el proceso documental.

Este fenómeno puede parecer a simple vista ilógico, pero lo realmente paradójico sería justamente lo contrario, que un mismo mensaje sometido a varios procesos documentales «memorizase» los procesos documentales previos a los que ha sido sometido, adquiriendo características nuevas en cada paso por la cadena documentaria. Afortunadamente no sucede de este modo. En el aspecto que nos afecta ahora, cada vez que un mensaje va a ser sometido a análisis es, a todos los efectos, un documento primario, y el análisis tiene como efecto la aparición de un documento nuevo, vinculado con el primario pero distinto, al que denominamos documento secundario.

Si ese mismo mensaje vuelve a ser analizado, se sigue comportando como un documento primario que dará origen, de nuevo, a un documento secundario. Y si ese documento secundario (es un caso hipotético que se puede dar en la práctica) es incorporado a su vez al fondo, adopta tras esa incorporación todas y cada una de las características de un documento primario, y por tanto, es capaz de engendrar un documento secundario que lo describe formalmente y en relación a su contenido.

Este fenómeno puede explicarse diciendo que el carácter recurrente del proceso documental tiene una consecuencia inmediata e irrenunciable: toda clasificación que adopte como criterio la situación del documento dentro del esquema de tratamientos o fases esenciales a los que puede ser sometido en un proceso de esta índole ha de ser necesariamente relativa, en ningún caso absoluta. Ello es así porque nada en el documento, considerado aislada e independientemente, 
indica si se trata de un documento primario o secundario, o si forma parte de una documentación primaria o secundaria. Expresándolo de otra manera, un documento cualquiera en sí no es primario ni secundario. Su consideración como primario o secundario dependerá exclusivamente de su situación, en un momento dado, dentro de la cadena de transformaciones medulares que pueden operarse sobre él.

Como consecuencia de lo expuesto, deducimos que al pasar desapercibido el carácter recurrente del proceso documental, han surgido aparentes problemas teóricos que en realidad no existían. El caso más llamativo a efectos de tipología documental consiste en concebir la documentación terciaria como la documentación derivada de la secundaria, siendo el ejemplo más conocido el de las bibliografías de bibliografías. Pero teniendo presente el carácter recurrente del proceso documentario y las consiguientes clasificaciones relativas que origina cuando se considera en sí mismo, convendremos en que una bibliografía de bibliografías, desde el momento en que se incorpora al fondo de una institución documental, se convierte automáticamente en un documento primario más, y al igual que los demás, será analizado al menos formalmente, dando lugar a una ficha (documento secundario) donde se anota el autor, pie de imprenta, etc.

Una de las causas que quizá más ha influido en la innecesaria (creo yo) multiplicación de categorías documentales que estamos analizando, ha sido sin duda la aparición de nuevos productos documentales acordes con las necesidades informativas, cada vez más complejas, de los usuarios. Este fenómeno, lógico por otra parte, ha conllevado la aparición de variedades de documentación secundaria tan sofisticadas que han dificultado enormemente la aplicación del criterio de originalidad, criterio que -como hemos comprobado- ha servido de punto de referencia permanente al estar incorporado desde siempre al concepto de documento primario.

No por ello es un problema nuevo. Basta recordar la dificultad teórica que plantea en este mismo plano un diccionario o una enciclopedia. Únicamente se ha extendido esta objeción al terreno de los documentos secundarios, cuando han dejado de limitarse a los tradicionales asientos bibliográficos.

Dado que el tratamiento documental ha sido desde siempre el enfoque esencial utilizado para caracterizar la documentación secundaria, la conclusión que obtenemos de este fenómeno, más obvia conforme evoluciona el quehacer documental, insiste en las ventajas teóricas de separar claramente la originalidad y el tratamiento analítico como criterios de clasificación. La definición aportada anteriormente de documentación primaria y secundaria se hace eco, cuando menos, de este aspecto que considero fundamental. 
Una vez deslindadas la originalidad y el tratamiento analítico como criterios de clasificación documental, que deberían aplicarse separadamente -insisto- en aras de una mayor racionalidad y coherencia teóricas, evitando así la aparición de objeciones de mayor o menor alcance, excepciones, e incluso parcelas de documentos no contemplados en ninguna categoría o de difícil adscripción a una de ellas, podemos ahondar brevemente en una dificultad esencial que conlleva la utilización de la originalidad como criterio tipológico.

El problema que plantea, de partida, la originalidad como enfoque para discernir clases documentales tiene su raíz más profunda en la existencia de dos fases de creación, si consideramos el proceso en su integridad. La primera alude a la creación del documento «inicial o primigenio», mientras que la segunda viene forzada por la creación del mensaje nuevo que incluye la fase de análisis. De hecho, los teóricos del resumen han destacado el factor creativo que incorpora siempre esta variedad de análisis de contenido (Pinto Molina, 1992).

No es la ocasión más adecuada para entrar en un debate tan complejo como éste. Tan solo pretendo llamar la atención sobre las ventajas teóricas que conllevaría separar claramente el criterio de originalidad en ambos casos (proceso inicial de creación del documento y proceso de creación del documento secundario), dadas las características tan dispares que poseen estas fases de creación (fuertes limitaciones en el objeto de estudio y mayor normalización técnica de elaboración en el análisis, entre otros muchos).

\section{Conclusiones}

Para concluir, reseñar que el examen de las clasificaciones documentales realizado muestra que el análisis tipológico debe procurar siempre la coherencia en sus planteamientos para evitar la presencia de casos particulares, excepciones y lo que es peor, la adición de categorías documentales que acojan conjuntos de documentos excluidos conforme a los criterios considerados inicialmente.

El empleo de un modelo teórico general de los procesos informativos involucrados en el quehacer documental puede erigirse, como he intentado mostrar en el caso de la tipología más debatida en los últimos años, en una vía útil de racionalización a la hora de afrontar la clasificación documental.

Como advertí al principio, mi intención ha sido únicamente ofrecer un enfoque más que pudiese servir para entablar un debate fructífero, con la esperanza de alcanzar finalmente una deseable normalización terminológica que abra la etapa de madurez investigadora y científica que todos ansiamos para la Documentación. 


\section{Referencias}

Amat i Noguera, N. (1988). Documentación científica y nuevas tecnologías de la información. $2^{\mathrm{a}}$ ed. Madrid : Pirámide, 1988.

Couture de Troismonts, R. (1975). Manual de técnicas en documentación. Buenos Aires : Marymar, 1975.

Currás, E. (1975). Tipos de documentos científicos. Métodos de clasificación. // Química e Industria. $21: 3$ (1975) 267-273.

Frank, O. (1964). Técnicas modernas de documentación e información. Buenos Aires : EUDEBA, 1964.

García Gutiérrez, A. L. (1984). Lingüística documental. Aplicación a la documentación de la comunicación social. Barcelona : Mitre, 1984.

Guinchat, C.; Menou, M. (1992). Introducción general a las ciencias y técnicas de la información y documentación. Madrid : CINDOC ; UNESCO, 1992.

López Yepes, J. (1978). Nuevos estudios de Documentación. Madrid : Instituto Nacional de Publicidad, 1978.

López Yepes, J. (1995). La aventura de la investigación científica. Madrid : Síntesis, 1995.

Mijailov, A.I.; Chernii, A.I.; Guiliarevskii, R.S. (1973). Fundamentos de la informática. La Habana : Nauka y Academia de Ciencias de Cuba, 1973. Vol. I.

Mijailov, A.I.; Guiliarevskii, R.S. (1968). An Introductory Course on Informatics / Documentation. UNESCO, FID, [1968].

Pinto Molina, M. (1992). El resumen documental: principios y métodos. Madrid ; Salamanca : F.G.S.R., 1992.

Scire. 3 : 1 (ene. -jun. 1997) 31-53 